\title{
RESEARCH
}

Open Access

\section{Oral administration of the cannabigerol derivative VCE-003.2 promotes subventricular zone neurogenesis and protects against mutant huntingtin-induced neurodegeneration}

José Aguareles ${ }^{1,2,3}$, Juan Paraíso-Luna ${ }^{1,2,3}$, Belén Palomares ${ }^{4,5,6}$, Raquel Bajo-Grañeras ${ }^{1,2,3}$, Carmen Navarrete , Andrea Ruiz-Calvo 1,2,3, Daniel García-Rincón ${ }^{1,2,3}$, Elena García-Taboada ${ }^{1,2,3}$, Manuel Guzmán 1,2,3,

Eduardo Muñoz ${ }^{4,5,6}$ and Ismael Galve-Roperh ${ }^{1,2,3^{*}}$ (D)

\begin{abstract}
Background: The administration of certain cannabinoids provides neuroprotection in models of neurodegenerative diseases by acting through various cellular and molecular mechanisms. Many cannabinoid actions in the nervous system are mediated by $\mathrm{CB}_{1}$ receptors, which can elicit psychotropic effects, but other targets devoid of psychotropic activity, including $\mathrm{CB}_{2}$ and nuclear PPARy receptors, can also be the target of specific cannabinoids.

Methods: We investigated the pro-neurogenic potential of the synthetic cannabigerol derivative, VCE-003.2, in striatal neurodegeneration by using adeno-associated viral expression of mutant huntingtin in vivo and mouse embryonic stem cell differentiation in vitro.

Results: Oral administration of VCE-003.2 protected striatal medium spiny neurons from mutant huntingtin-induced damage, attenuated neuroinflammation and improved motor performance. VCE-003.2 bioavailability was characterized and the potential undesired side effects were evaluated by analyzing hepatotoxicity after chronic treatment. VCE-003.2 promoted subventricular zone progenitor mobilization, increased doublecortin-positive migrating neuroblasts towards the injured area, and enhanced effective neurogenesis. Moreover, we demonstrated the proneurogenic activity of VCE-003.2 in embryonic stem cells. VCE-003.2 was able to increase neuroblast formation and striatal-like CTIP2mediated neurogenesis.
\end{abstract}

Conclusions: The cannabigerol derivative VCE-003.2 improves subventricular zone-derived neurogenesis in response to mutant huntingtin-induced neurodegeneration, and is neuroprotective by oral administration.

Keywords: Cannabinoid, Huntingtin, Neurodegeneration, Neurogenesis, PPAR

\footnotetext{
* Correspondence: igr@quim.ucm.es

${ }^{1}$ Instituto Ramón y Cajal de Investigación Sanitaria (IRYCIS), Ctra. Colmenar

Viejo, km, 9100 Madrid, Spain

Departamento de Bioquímica y Biología Molecular and Instituto

Universitario de Investigación Neuroquímica, Universidad Complutense,

Madrid, Spain

Full list of author information is available at the end of the article
}

(c) The Author(s). 2019 Open Access This article is distributed under the terms of the Creative Commons Attribution 4.0 International License (http://creativecommons.org/licenses/by/4.0/), which permits unrestricted use, distribution, and reproduction in any medium, provided you give appropriate credit to the original author(s) and the source, provide a link to the Creative Commons license, and indicate if changes were made. The Creative Commons Public Domain Dedication waiver (http://creativecommons.org/publicdomain/zero/1.0/) applies to the data made available in this article, unless otherwise stated. 


\section{Background}

Huntington's disease (HD) is a monogenic neurodegenerative disease produced by the expression of mutant huntingtin (htt) protein with expanded glutamine repeats in the N-terminal portion of the protein [1]. Mutant htt expression induces striatal atrophy and medium spiny neuron (MSN) death, which is responsible for the characteristic motor symptoms of the disease. The length of the polyglutamine tract expansion in the htt gene, higher than 40 repeats, is closely associated with disease onset. Hence, although HD neurodegeneration occurs in adult brain, mutant htt expression is also known to interfere with normal neurodevelopment at several levels. Mutant huntingtin interferes with the activity of various transcription factors (GSX2+, ASCL1+, ISLT1+, NKX2.1) that are essential in controlling cortical and striatal neurogenesis [2, 3]. Among others, mutant huntingtin decreases NeuroD1 activity, a transcription factor that acts as a major confluence node of different neurodevelopmental gene pathways [3]. Mutant huntingtin also alters the mode of division of subventricular zone (SVZ) progenitors by influencing mitotic spindle orientation, that in turn controls asymmetric cell division and neurogenesis [4]. Moreover, mutant huntingtin expression interferes with projection neuron migration as normal huntingtin regulates Rab11-mediated N-cadherin trafficking [5].

Certain cannabinoids, the main active compounds of Cannabis sativa, and their endogenous counterparts 2-arachidonoylglycerol and anandamide exert symptomatic relief in various neurodegenerative and neuroinflammatory conditions [6]. Neuroprotection in mouse HD models as induced by $\Delta^{9}$-tetrahydrocannabinol (THC), the most abundant bioactive compound of Cannabis sativa, occurs at least in part in a cell-autonomous manner via the $\mathrm{CB}_{1}$ receptor [7]. Unfortunately, considering that $\mathrm{CB}_{1}$ receptor levels notably diminish at early stages of HD [8-10], and that $\mathrm{CB}_{1}$ receptor agonists produce undesired psychoactive effects [11], the development of clinical treatments based on $\mathrm{CB}_{1}$-receptor acting cannabinoids constitutes an extremely complicated task. Hence, investigating the potential use of cannabinoids other than THC, with different pharmacological profiles, constitutes an interesting research area for the development of new candidate molecules with reduced unwanted actions. Cannabigerol (CBG) is a non-psychoactive cannabinoid that has been tested as a candidate molecule for pharmacological therapies in HD experimental models [12]. CBG via the nuclear receptor peroxisome proliferator-activated receptor- $\gamma$ (PPAR $\gamma$ ) alleviates motor symptoms, neuroinflammation and neurodegeneration in murine models of HD based on either striatal neurotoxicity (3-nitropropionic acid injection model) or transgenic expression of human mutant huntingtin exon 1 (R6/2 model) [12]. Of interest, thiazolidinedione-induced PPAR $\gamma$ activation is neuroprotective against mutant huntingtin-induced cell death and reduce huntingtin aggregates in the brain [13]. In order to improve the pharmacological profile of CBG, chemical modifications were introduced, leading to the CBG quinone derivatives VCE-003 and VCE-003.2 [14, 15]. VCE-003.2 ([2-(3,7-dimethyl-octa-2, 6-dienyl)-6-ethylamino-3-hydroxy-5-pentyl-(1,4) benzoquinone]), an aminoquinone derivative of CBG, improves the pharmacological profile of VCE-003 by eliminating the characteristic side effects of potent PPARY activators. Fundamentally, VCE-003.2 is neuroprotective in the quinolinic acid-administration model of HD and increases neural progenitor survival [14]. In the present study, we evaluated the neuroprotective efficacy of oral VCE-003.2 administration. Noteworthy, oral VCE-003.2 was neuroprotective against mutant huntingtin-induced damage, and also improved SVZ-derived neurogenesis. Overall, these findings provide further support to the neuroprotective and antiinflammatory activities of VCE-003.2, and suggests its potential as a disease-modifying agent, considering its ability to improve the endogenous neurogenic response.

\section{Methods \\ Cell culture and reagents}

All reagents, unless indicated, were from Sigma-Aldrich (St. Louis, MO, USA). The synthesis and structure of VCE-003.2 were previously described [14, 15]. Mouse embryonic teratocarcinoma P19 were cultured in high-glucose DMEM (Invitrogen) supplemented with $10 \%$ fetal bovine serum and $1 \%$ penicillin/streptomycin. P19 cells were plated in 24-well plates and transfected with Lipofectamine 2000 reagent according to the manufacture's protocol (Invitrogen). Twenty-four hours post transfection, cells were collected for RNA extraction or luciferase assay determinations. P19 neurosphere formation assay was performed using dissociated P19 cells cultured in high-glucose DMEM (Invitrogen) supplemented with $5 \%$ of fetal bovine serum and $0.5 \mu \mathrm{M}$ retinoic acid. Twenty-four hours later the mean neurosphere size was quantified. Luciferase construct with the MAR sequence A4 of the Ctip2 promoter was kindly provided ( $R$. Grosschedl, Max-Planck-Institute of Immunobiology and Epigenetics, Freiburg, Germany).

\section{Mouse embryonic stem cell differentiation}

R1 mouse embryonic stem (mES) cell line was grown on gelatin 0.1\%, in Knockout DMEM supplemented with 20\% Knockout Serum Replacement, 1000 U ml-1 of LIF, $0.1 \mathrm{mM}$ of non-essential amino acids, $2 \mathrm{mM}$ ultraglutamine, $50 \mathrm{Uml}-1$ of penicillin and streptomycin and 0.1 $\mathrm{mM}$ of 2-mercaptoethanol. Cells were then differentiated at low density in Defined Default Medium (DDM) containing DMEM/F12 + GlutaMAX supplemented with N2 supplement $(1 \times), 5 \mathrm{mM}$ of Hepes Buffer, $0.1 \mathrm{mM}$ of 
non-essential amino acids, $1 \mathrm{mM}$ of sodium pyruvate, $2.5 \mathrm{mg} \mathrm{ml}-1$ of AlbuMax-I, $30 \mathrm{mM}$ of D-Glucose, 0.1 $\mathrm{mM}$ of non-essential amino acids, $0.1 \mathrm{mM}$ of 2-mercaptoethanol, $50 \mathrm{U} \mathrm{ml-1}$ of penicillin and streptomycin for 12 days. The cells were then plated on polylysine/laminin-coated dishes in 50\% DDM and 50\% Neurobasal/B27 containing Neurobasal supplemented with B27 (1×), $2 \mathrm{mM}$ of Ultraglutamine and $50 \mathrm{U} \mathrm{ml}-1$ of penicillin and streptomycin for 9 days.

\section{Luciferase transcriptional assays}

To study CTIP2 transcriptional activity P19 cells were seeded in 24-well plates and transiently co-transfected with the luciferase reporter vector MARS-A4-luc [16] using Roti-Fect (Carl Roth, Karlsruhe, Germany) following the manufacturer's instructions. To correct for transfection efficacy, $100 \mathrm{ng}$ Renilla luciferase (pRL-CMV) was also cotransfected. After stimulation, the luciferase activities were quantified using Dual-Luciferase Assay (Promega, Madison, WI, USA).

\section{Mutant huntingtin-induced neurodegeneration}

Male C57BL/6 N mice (10 weeks old) were housed under standard conditions (12-h light/dark cycle) in groups with access to food and water ad libitum. All experiments were performed in accordance with European Union guidelines and approved by the Animal Research Ethics Committee of Complutense and Córdoba University. Procedures were designed to minimize the number of animals used and their suffering. Constructs expressing CFP-tagged human huntingtin exon 1 harboring a pathogenic polyQ tract of 94 CAG repeats or a normal, non-pathogenic polyQ tract of 16 CAG repeats (kindly provided by Dr. José J. Lucas, Severo Ochoa Molecular Biology Center, Madrid, Spain) were employed using an AAV1/AAV2 mixed serotype, generated by polyethyleneimine transfection of HEK293T cells and subsequent purification in iodixanol gradient. Vectors were injected stereotactically (in $3 \mu \mathrm{l}$ PBS) into the dorsal striatum in a bilateral manner at coordinates ( $\mathrm{mm}$ to bregma): antero-posterior +0.5 , lateral \pm 2.5 , dorso-ventral -3.5 as previously described [17]. VCE-003.2 $(10 \mathrm{mg} / \mathrm{kg})$ or vehicle (sesame oil) were orally administered once daily (Fig. 1), and for neurogenesis experiments BrdU $(100 \mathrm{mg} / \mathrm{kg})$ was administered i.p. twice daily on the first week after viral injection. RotaRod test was conducted prior to drug injections to avoid acute effects of the compounds under investigation. RotaRod started at $4 \mathrm{rpm}$, with an acceleration rate of $6 \mathrm{rpm} / \mathrm{min}$ until either maximum speed is reached or the mouse falls from the apparatus. Maximum time assay was $10 \mathrm{~min}$. Basal RotaRod performance was determined 6 days prior to striatal injury in 3 consecutive days with 3 trials/day (30 min of rest between each trial), and groups with equivalent motor function were assigned. RotaRod test was performed during 3 consecutive days prior to sacrifice and plasma was obtained for peripheral biomarker analyses. All experiments included a minimum of 6 mice per condition. The precise number of animals analyzed in each experiment is indicated in the corresponding figure legends.

\section{Gene expression}

Total RNA was isolated from striate using the Qiagen RNeasy Lipid kit (Qiagen, Germany). Total RNA $(1 \mu \mathrm{g})$ was retrotranscribed using the iScript cDNA Synthesis Kit and the CDNA analyzed by real-time PCR using the iQTM SYBR Green Supermix and a CFX96 Real-time PCR Detection System (Bio-Rad; Hercules, CA, USA). The HPRT gene was used to standardize mRNA expression in each sample. Gene expression was quantified using the $2^{-\Delta \Delta \mathrm{Ct}}$ method and the percentage of relative expression against controls (untreated cells or mice) was

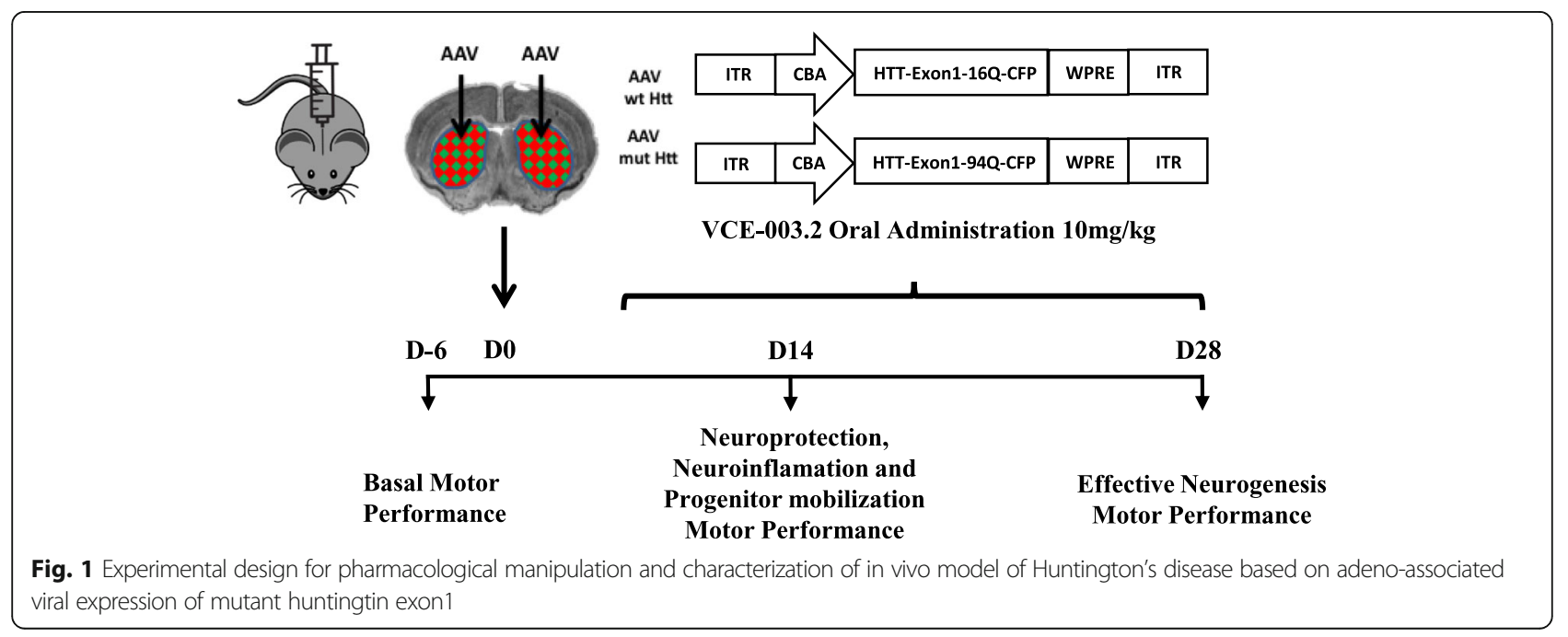


represented. The primers used in this study were: IL-6; forward: 5'GAACAACGATGATGCACTTGC3'; reverse: 5'TCCAGGTAGCTATGGTACTCC3'; TNF $\alpha$; forward: 5'AGAGGCACTCCC CCAAAAGA-3; reverse: CGAT CACCCCGAAGTTCCCATT.

\section{Pharmacokinetics}

Six-week old male Sprague Dawley rats (Janvier Labs, France) were located in the rodent area of Eurofins ADME Bioanalyses (Vergèze, France) and housed under standard conditions (12-h light/dark cycle) in groups with access to food and water ad libitum. Each animal was identified by an ear tag and examined for general health and welfare. Process, treatment and euthanasia were conducted according to the current procedures in use at Eurofins ADME Bioanalyses. Animals were treated with a single intravenous bolus of VCE-003.2 $(10 \mathrm{mg} / \mathrm{Kg}$ in DMSO) or with oral VCE-003.2 $(50 \mathrm{mg} / \mathrm{Kg}$ in sesame oil). At the prescribed times, blood $(0.5 \mathrm{ml})$ was collected using a capillary tube and plasma frozen at $-20^{\circ} \mathrm{C}$ until analysis. After $24 \mathrm{~h}$, the animals were anesthetized and perfused with $20 \mathrm{~mL}$ of saline solution directly into the heart to extract the maximal blood sample from the brain. Plasma samples $(100 \mu \mathrm{l})$ were mixed with $300 \mu \mathrm{l}$ of acetonitrile and after protein precipitation, analysis of VCE-003.2 content was performed using LC-MS/MS (3 animals per each time point). For brain samples, the tissues were homogenized with an Ultra-turrax ${ }^{\circ}$ using UHQ water $(1 / 1, w / w) .100 \mu$ l of each homogenate was mixed with $300 \mu$ of acetonitrile and the mixture centrifuged for $5 \mathrm{~min}$ at 25,000 g. Brain homogenate supernatants were directly measured by LC-MS/MS. Previous studies have shown that there are not significant differences between mice and rats in the main pharmacokinetic parameters of different cannabinoids, including CBG [18]. As the dose used here was different between i.v. and oral routes of administration, bioavailability was calculated taking into account the dose as follows: [AUCt (oral)/dose (oral)]/[AUCt(i.v.)/ dose(i.v.)].

\section{Proteome array}

Plasma samples from wild-type and mutant huntingtinexpressing C57BL/6 $\mathrm{N}$ mice were pooled ( $n=6$ animals per group) and analyzed for cytokine and adipokine expression. The Proteome Profiler Mouse XL Cytokine Array and the Proteome Profiler Mouse Adipokine Array (R\&D Systems) were used according to the manufacturer's protocols to obtain protein expression profiles using $100 \mu \mathrm{l}$ plasma samples. Spot density was determined using Quick Spots image analysis software (R\&D Systems).

\section{Immunofluorescence and confocal microscopy}

Free floating coronal brain slices $(30 \mu \mathrm{m})$ were processed as previously described [17]. In brief, after blocking with $10 \%$ goat serum, brain sections were incubated with the indicated primary antibodies followed by secondary antibody incubation ( $2 \mathrm{~h}$ at room temperature). The appropriate mouse, rat and rabbit highly cross-adsorbed AlexaFluor 488, AlexaFluor 594 and AlexaFluor 647 secondary antibodies (1:500; Molecular Probes, Leyden, The Netherlands) were used. Samples were subsequently incubated with DAPI (1:5000, Roche) for $10 \mathrm{~min}$, washed with PBS and mounted in Mowiol. All immunofluorescence data were obtained in a blinded manner by independent observers in a minimum of 6 correlative slices, from 1-in-10 series located between -0.4 to $+1.6 \mathrm{~mm}$ to bregma. The lateral SVZ zone was delineated by using DAPI-counterstained cell nuclei, and analyses were performed in the upper dorsal tier, in which positively-labelled cells and immunoreactivity were quantified not beyond $100 \mu \mathrm{m}$ of the SVZ. Confocal fluorescence images were acquired by using LAS-X software (Wetzlar, Germany) and SP8 microscope with 2 passes by Kalman filter, a 1024X1024 collection box, and pinhole AU 1. Double-labelled positive cells (GFAP/ $\mathrm{Ki}-67$ and BrdU/NeuN cells) were counted at a magnification of $40 \times$. Cells were quantified within a $20 \times 20 \mu \mathrm{m}$ counting frame, which randomly sampled within a $122.8 \times 68.9 \mu \mathrm{m}$ counting grid. Cells that contacted the lateral or upper exclusion plane were excluded. The total number of cells counted was divided by the number of sampled counting frames and multiplied by its size to obtain the density of positive cells. Co-localization was confirmed by orthogonal projection of 18 z-stack files (1- $\mu \mathrm{m}$ each), and data were expressed as cells $/ \mathrm{mm}^{2}$. Neurodegeneration and glial activation was determined by dopamine- and cAMP-regulated phosphoprotein of $32 \mathrm{kDa}$ mouse anti-DARPP32 (1:500 BD Transduction Laboratories, Lexington, KY), rabbit anti-Iba-1 (1:500 Wako Pure Chemical, Osaka, Japan) and mouse anti-GFAP-Cy3 (1:500 Sigma, St. Louis, MO) immunostaining, and quantified with Image-J software designed by the National Institutes of Health (NIH; Bethesda, MD, USA). Neurogenesis and SVZ-progenitor mobilization were characterized by immunofluorescence with rat anti-CTIP2 antibodies (1:500 Abcam, Cambridge, United Kingdom). Rabbit anti-Doublecortin (1:1000 from Abcam), rat anti-BrdU (1:250 from Abcam) and mouse anti-NeuN (1:500 from Chemicon) antibodies, or rabbit anti-GFAP and rabbit anti-Ki67 (1:400 from Invitrogen and 1:500 from ThermoScientific).

\section{Statistical analysis}

In vitro data are expressed as mean \pm S.D. and in vivo results are represented as mean \pm SEM. Data were subjected 
to Kolmogorov-Smirnov normality test and then, differences were analyzed by one-way ANOVA followed by Tukey post hoc test. $P<0.05$ was considered significant. Statistical analysis was performed using GraphPad Prism version 5.01 and is shown in figure legends. Images were analyzed and quantified using the ImageJ.

\section{Results}

\section{VCE-003.2 exerts a pro-neurogenic effect in vitro}

To investigate the pro-neurogenic potential of VCE-003.2 we analyzed its influence in ES-neuronal differentiation. The R1 line of mouse ES cells was treated with VCE-003.2 during neural differentiation for 21 days and we assessed CTIP2-positive striatal MSN differentiation [19]. Immunofluorescence quantification revealed that VCE-003.2 increased the number of CTIP2-positive cells as well as doublecortin immunoreactivity (Fig. 2a-b). Next, using neuralized mouse embryonic teratocarcinoma P19 cells, we performed CTIP2 transcriptional activity assays by transfecting a luciferase reporter construct (A4-Mar) corresponding to one of the regulatory MARS sequences of the CTIP2 promoter. VCE-003.2 promoted neuronal-like differentiation as revealed by CTIP2 reporter activation (Fig. 2c). Furthermore, using a P19 neurosphere formation assay, VCE-003.2 generated larger neurospheres than vehicle-treated cells $(367.90 \pm 15.20 \mu \mathrm{m}$ and $268.70 \pm$ $9.20 \mu \mathrm{m}$, respectively; Fig. 2d). These results support a pro-neurogenic action of VCE-003.2 on neural stem cell differentiation.

\section{Pharmacokinetics and bioavailability of VCE-003.2}

As VCE-003.2 was previously shown to exert a neuroprotective action in preclinical HD models, and considering its pro-neurogenic profile, we evaluated the pathophysiological impact and potential therapeutic value of VCE-003.2 after oral administration. Pharmacokinetic analyses were performed in rats after oral administration of VCE-003.2 $(50 \mathrm{mg} / \mathrm{kg})$ dissolved in sesame oil. Plasma VCE-003.2 levels peaked at $8 \mathrm{~h}$ (Tmax) and then slowly declined to basal levels. Oral VCE-003.2 resulted in $13.8 \%$ bioavailability and after $24 \mathrm{~h}$ the concentration of the compound in the brain was similar upon oral or i.v. treatment (Table 1). We also investigated some critical ADME/Tox parameters. By using human liver microsomes we found that VCE-003.2 undergoes a rapid intrinsic clearance in vitro, which was similar to the parental compound CBG (Additional file 1). Moreover, VCE-003.2 did not inhibit significantly the activity of relevant cytochrome P450 isoforms (Additional file 2). We also determined the potential hepatotoxicity of chronic VCE-003.2 administration by hematoxylin-eosin staining. VCE-003.2- and vehicle-treated mouse-derived livers did not show any evidence of fibrosis, steatosis, vacuolization, ballooning or inflammation (data not shown). In addition, VCE-003.2 administration did not inhibit hERG channel activity, suggesting a potential lack of cardiotoxicity (Additional file 3), and it was not genotoxic as assessed by AMES assays (Additional file 4). We also determined the impact of VCE-003.2 administration on peripheral biomarkers by quantifying the levels of cytokines and other soluble mediators. Viral infection lead to changes in various neuroinflammation biomarkers, notably C-reactive protein and pentraxins 2 , 3 were increased by htt94Q and these changes were reverted by VCE-003.2 treatment (Additional file 5). These data indicate that mutant huntingtin induces a process of neuroinflammation that results in the release of soluble factors that can be quantified in plasma and normalized by VCE- 003.2 oral administration.

\section{Oral administration of VCE-003.2 attenuates neuroinflammation and is neuroprotective in a viral model of mutant huntingtin expression}

To evaluate the neuroprotective profile of oral VCE-003.2 administration, a viral model of HD was employed [20] in which wild-type mice were subjected to bilateral intrastriatal injection of adeno-associated virus (AAV) expressing either exon 1 of human pathogenic huntingtin with a polyQ tract of 94 CAG repeats, or a normal, non-pathogenic huntingtin with a polyQ tract of 16 CAG repeats (AAV-htt16Q and AAV-htt94Q, respectively), and treated with VCE-003.2 (10 mg/kg/ day). Whereas expression of (exon1)-huntingtin-16Q during 14 days did not affect motor coordination, mutant huntingtin-94Q decreased RotaRod latency to fall (Fig. 3a). Motor impairment in htt94Q mice was accompanied by profound activation of microglial cells, as evidenced by Iba1 confocal immunofluorescence, in the area surrounding the infection site (Fig. 3b). Mice treated with VCE-003.2 performed better in the RotaRod test than their vehicle-treated AAV-htt94Q counterparts, and showed reduced microglial activation (Fig. 3a-b). Furthermore, VCE-003.2 administration prevented htt94Q-induced MSN degeneration as evidenced by DARPP-32 and NeuN immunofluorescence (Fig. 4a-b). These results are in line with previous findings on the neuroprotective ability of VCE-003.2 in toxin-based models of neurodegeneration $[14,21]$ and expand its potential clinical profile since oral administration was as effective as i.p. delivery. Likewise, oral VCE-003.2 administration was also neuroprotective and anti-inflammatory in the 3-NP model of striatal neurodegeneration (Additional file 6).

\section{Oral administration of VCE- 003.2 promotes striatal neurogenesis}

The neuroprotective action of oral VCE-003.2 and its pro-neurogenic impact in vitro prompted us to investigate if this compound could contribute to striatal 
a

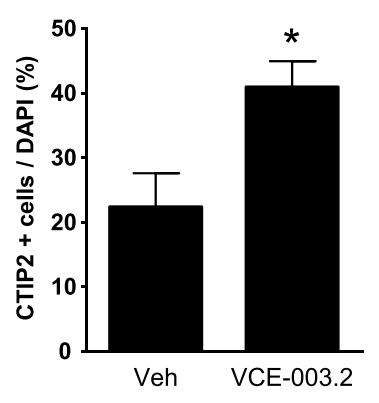

b

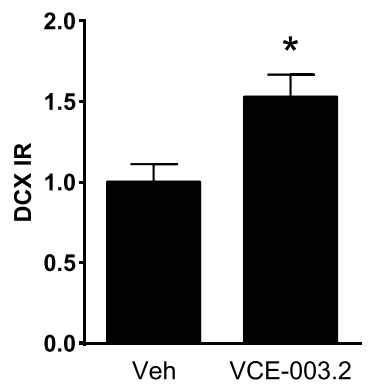

C

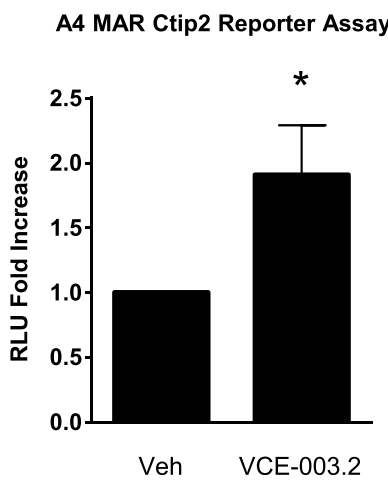

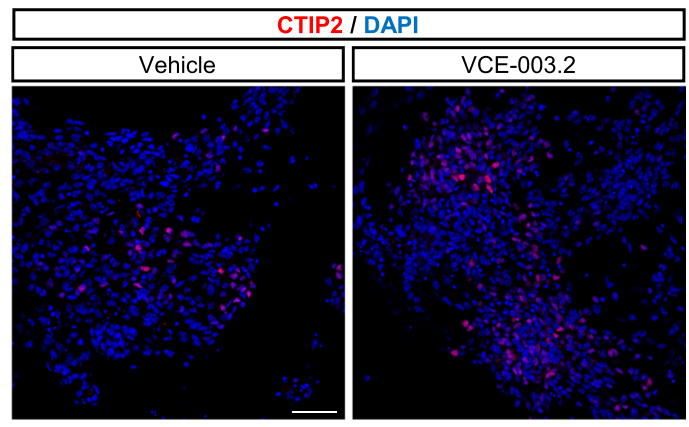

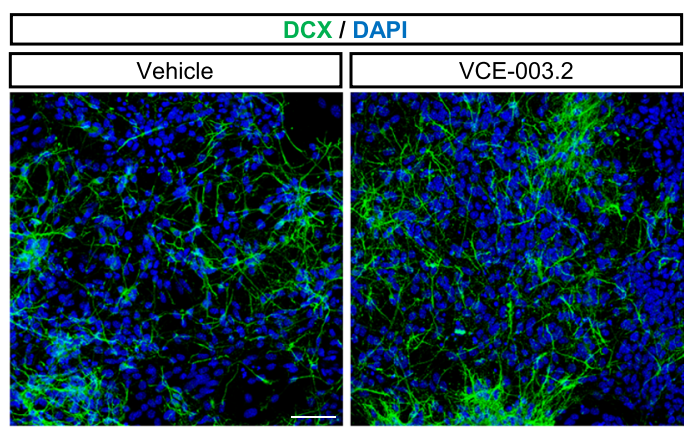

d
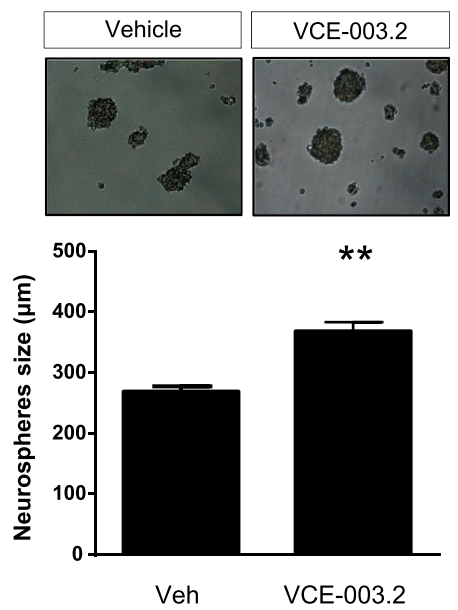

Fig. 2 VCE-003.2 exerts a pro-neurogenic effect in vitro. a-b Mouse embryonic stem cells (R1 line) were treated with Vehicle, VCE-003.2 (500 nM) during neural differentiation for 21 days. Representative immunofluorescence images and quantification of CTIP2- and doublecortin-positive cells is shown $(n=3)$. $\mathbf{c}$ Luciferase reporter assay of the A4-MARS sequence of the CTIP2 locus was performed $24 \mathrm{~h}$ after P19 cell transfection under neuronal differentiation conditions and subject to pharmacological regulation as above. $\mathbf{d}$ P19 neurosphere formation assay was performed by culturing the cells for $24 \mathrm{~h}$ in the presence of Vehicle or VCE-003.2. Statistics: Unpaired t-test vs Vehicle $\mathbf{a} * p<0.05 ; \mathrm{t}=2.82 ; \mathrm{df}=4 ; 95 \%$ Confidence interval $(C l)=0.3149$ to $36.85 ; R^{2}=0.66 . \mathbf{b} * p<0.05 ; t=2.91 ; d f=4 ; 95 \% C l=0.02$ to $1.03 ; R^{2}=0.67 . \mathbf{c}^{*} p<0.05 ; t=2.87 ; d f=5 ; 95 \% C l=0.09$ to $1.72 ;$ $R^{2}=0.62 . \mathbf{d}^{* *}<0.01 \mathrm{t}=5.91 ; \mathrm{df}=362 ; 95 \% \mathrm{Cl}=66.20$ to $132.20 ; \mathrm{R} 2=0.08$. Scale bar, $50 \mu \mathrm{m}$

Table 1 Pharmacokinetic parameters of VCE-003.2. Pharmacokinetic parameters of VCE-003.2 in plasma following a single intravenous (i.v.) $(10 \mathrm{mg} / \mathrm{kg})$ and oral $(50 \mathrm{mg} / \mathrm{kg})$ dose in Sprague Dawley rats

\begin{tabular}{lllllll}
\hline Compound & Route & Cmax $(\mathrm{ng} / \mathrm{mL})$ & $T \max (\mathrm{h})$ & AUCt $\left.\mathrm{ng} / \mathrm{mL}{ }^{*} \mathrm{~h}\right)$ & Bioavailability & Brain Concentration $(24 \mathrm{~h})(\mathrm{ng} / \mathrm{mL})$ \\
\hline VCE-003.2 & IV & 83160 & 0.08 & 475094.96 & & $93.7 \pm 37.7$ \\
VCE-003.2 & ORAL & 20266.67 & 8 & 327154.14 & $13.77 \%$ & $86.8 \pm 34.0$ \\
\hline
\end{tabular}




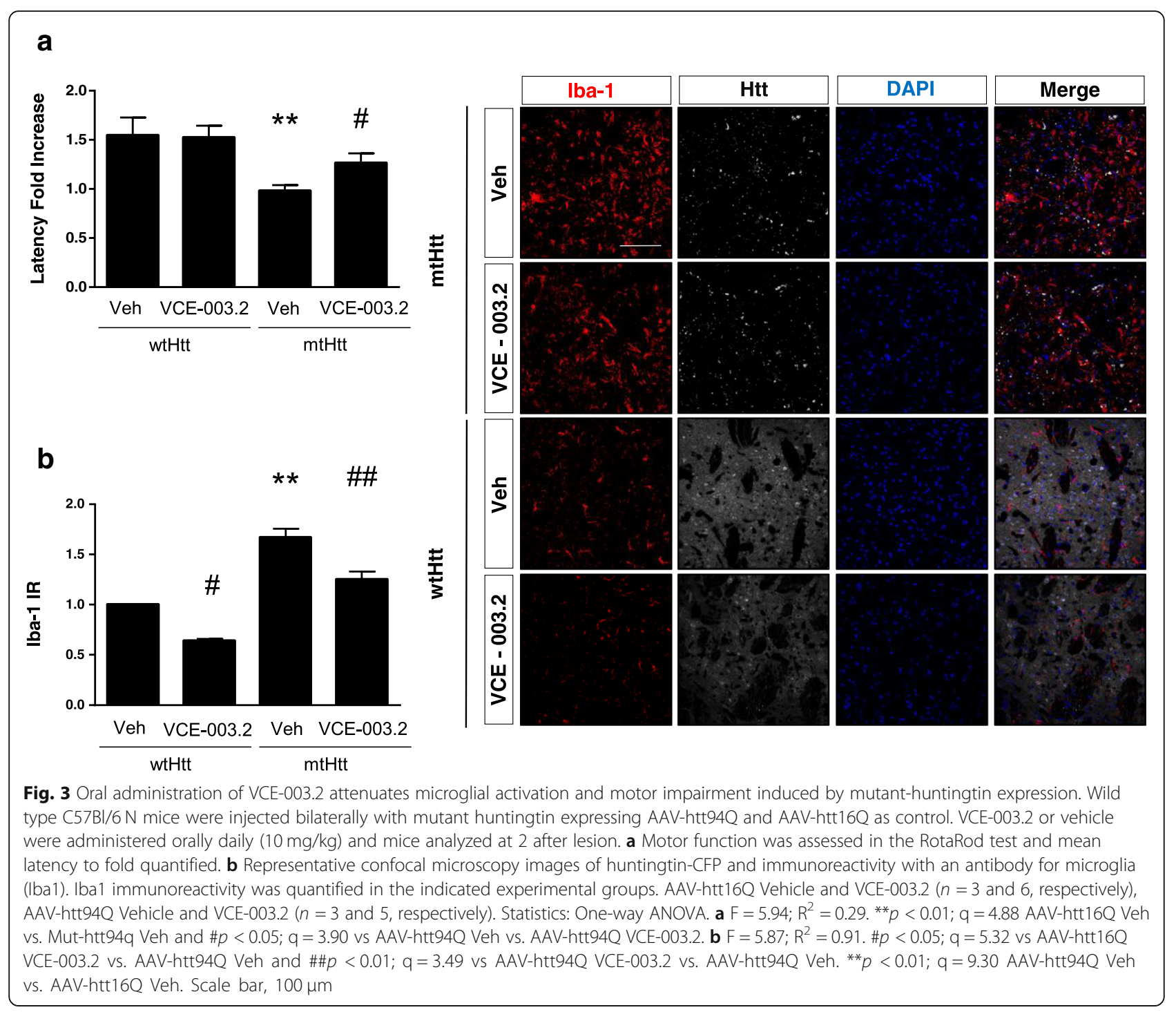

neurorepair in vivo by promoting SVZ-derived neurogenesis. We analyzed the SVZ neural stem cell population, identified as double-labelled GFAP/Ki-67 cells, which represents the radial glia type B cell compartment. VCE-003.2 increased the number of proliferating GFAP-positive cells in AAV-htt94Q-injected mice, indicating its positive impact on NSC mobilization (Fig. 5). Next, SVZ-derived neural progenitors were identified by immunofluorescence against Ascl1 (a transcription factor characteristic of the transit amplifying progenitor subpopulation). Mutant huntingtin expression induced an increase in $\mathrm{Ascl}^{+}$cell number, and VCE-003.2 administration further promoted Ascl1-positive cell expansion in AAV-htt94Q-mice (Fig. 6). To determine the impact of VCE-003.2 on striatal neurogenesis we next evaluated doublecortin-positive neuroblasts after 30 days of AAV-mediated huntingtin expression and daily VCE-003.2 administration. AAV-htt94Q-induced injury resulted in a slight increase in neuroblast formation (Fig. 7a) and effective neurogenesis $\left(\mathrm{BrdU}^{+} \mathrm{NeuN}^{+}\right.$cells) (Fig. 7b) as compared to AAV-htt16Q. Oral administration of VCE-003.2 was effective in promoting neurogenesis in AAV-htt16Q- and AAV-htt94Q-treated mice, both determined as increased doublecortin-expressing cells and double-positive NeuN/BrdU neurons (Fig. 7a-b). Hence, oral VCE-003.2 administration is able to restore striatal neurogenesis affected by mutant huntingtin expression.

\section{Discussion}

VCE-003.2 is an aminoquinone derivative of CBG that has been designated by the FDA as an orphan drug for HD treatment (www.accessdata.fda.gov/scripts/opdlisting/oopd/detailedIndex.cfm?cfgridkey=623717). In the present study, we demonstrate the pro-neurogenic activity of this cannabinoid derivative in a preclinical model 


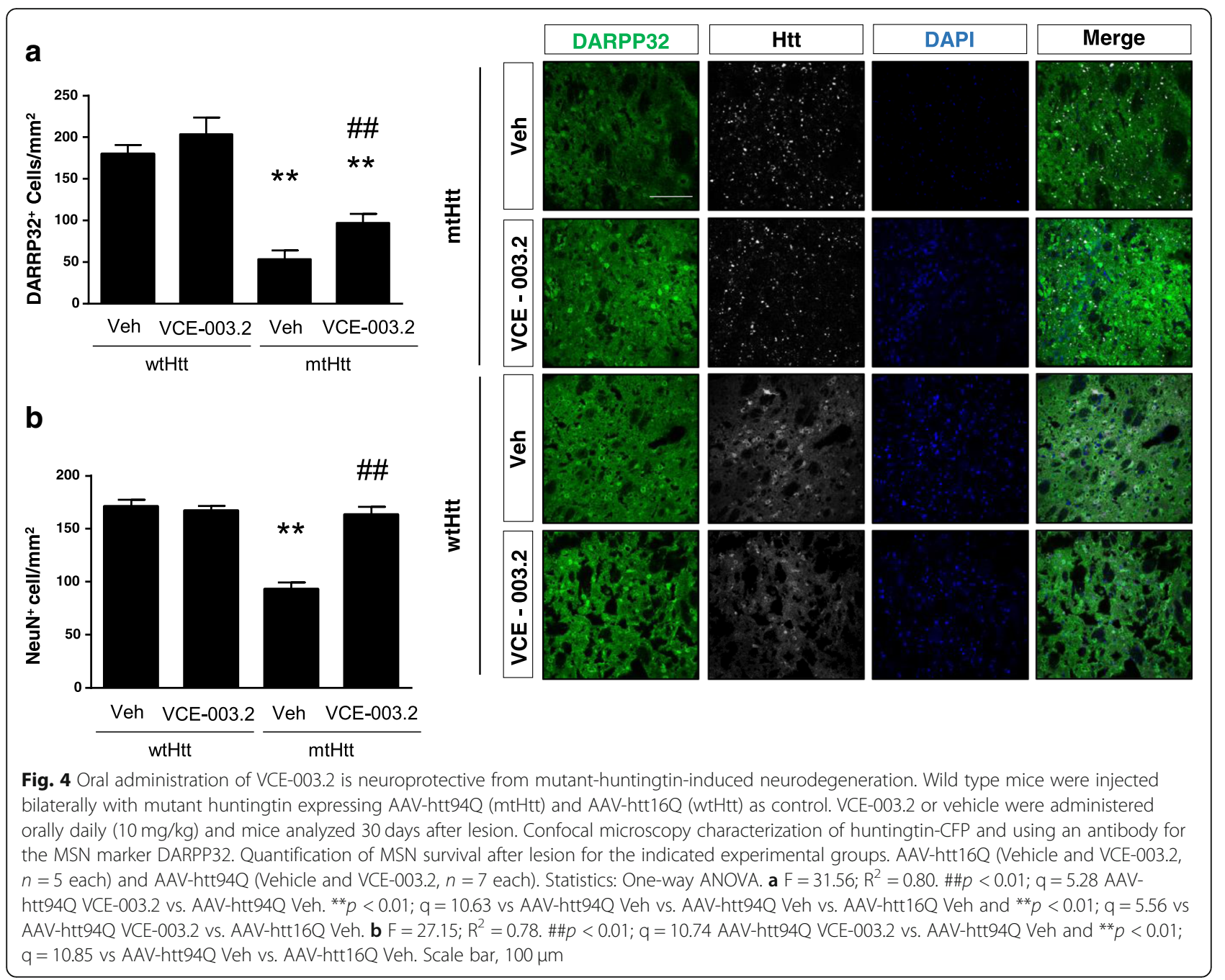

of HD that adds to its neuroprotective activity. Oral administration of VCE-003.2 exerted an anti-inflammatory and neuroprotective action in a HD experimental model. In addition, VCE-003.2 was able to augment mutant huntingtin-induced SVZ-derived neurogenesis, thus favoring neural stem cell mobilization (double-labelled $\mathrm{GFAP}^{+}$/ Ki- $67^{+}$and Ascl $^{+}{ }^{+}$cells), neuronal differentiation (doublecortin $^{+}$cells) and effective neurogenesis (double-labelled $\mathrm{Brdu}^{+} / \mathrm{NeuN}^{+}$cells). In agreement with previous studies, mutant huntingtin expression induced a pro-neurogenic response that was evident by the trend towards increased $\mathrm{Ascl}^{+}, \mathrm{Dcx}^{+}$and double-labelled $\mathrm{BrdU}^{+} / \mathrm{NeuN}^{+}$cells. The molecular signals and mechanisms underlying injuryinduced neurogenesis are diverse, and numerous therapeutic approaches aim to promote this endogenous process strategy [22]. Hence, the results obtained in this study support that striatal neurogenesis is improved by oral VCE-003.2 administration. This new mechanism of action of VCE-003.2 is relevant when considering its potential clinical applications, as it suggests that this molecule could constitute a disease-modifying drug rather than merely symptom-palliative. It is worth noting that the preclinical model of HD employed in this study is based on the expression of exon 1 of either mutant huntingtin or normal, non-pathogenic huntingtin. The validity of this approach for mechanistic and pharmacological investigations is demonstrated by the high number of studies using it [23]. However, improved animal models, for example based on the expression of full-length huntingtin, are likely to provide novel insights of additional aspects of $\mathrm{HD}$.

The use of plant derived-cannabinoid ligands has been proposed to exert symptomatic relief of motor symptoms in neurodegenerative diseases, including HD-associated dystonia and chorea, levodopa-induced dyskinesia and tremor in Parkinson's disease, and multiple sclerosis-associated spasticity [6, 24]. Despite the great interest in the therapeutic potential of cannabinoids in neurodegenerative diseases, the undesired side-effects of $\mathrm{CB}_{1}$ receptor agonists significantly limit 


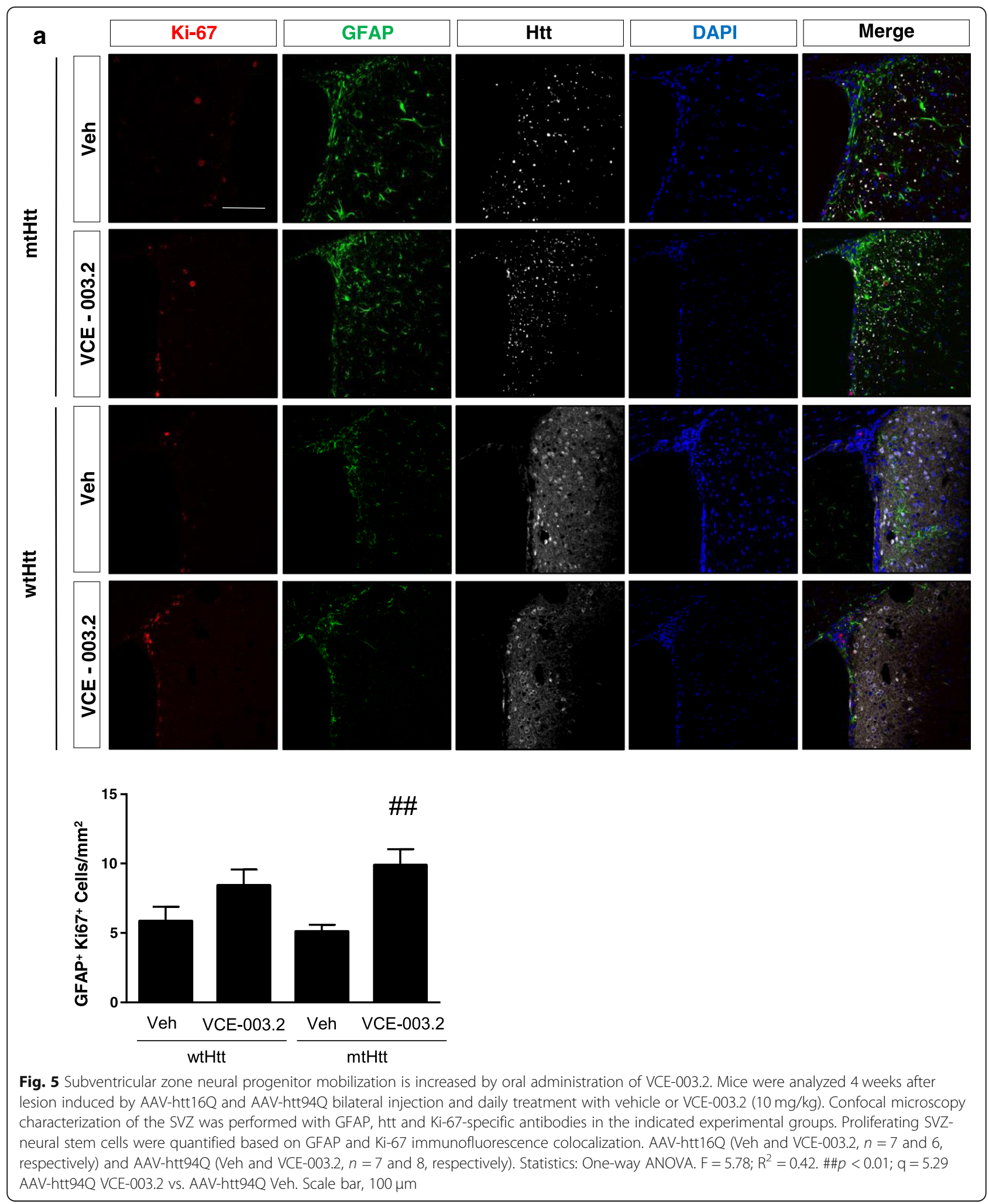

their use in clinical practice. In addition, during HD progression presynaptic $C_{1}$ receptor levels decline very early, even at presymptomatic stages $[7,9,10]$. Hence, despite the fact that corticostriatal projections preserve
$\mathrm{CB}_{1}$ receptor expression [17], the use of $\mathrm{CB}_{1}$ agonists alone may have a limited therapeutic window, and the development of new cannabinoid-derived molecules acting via different signaling mechanisms and with reduced 


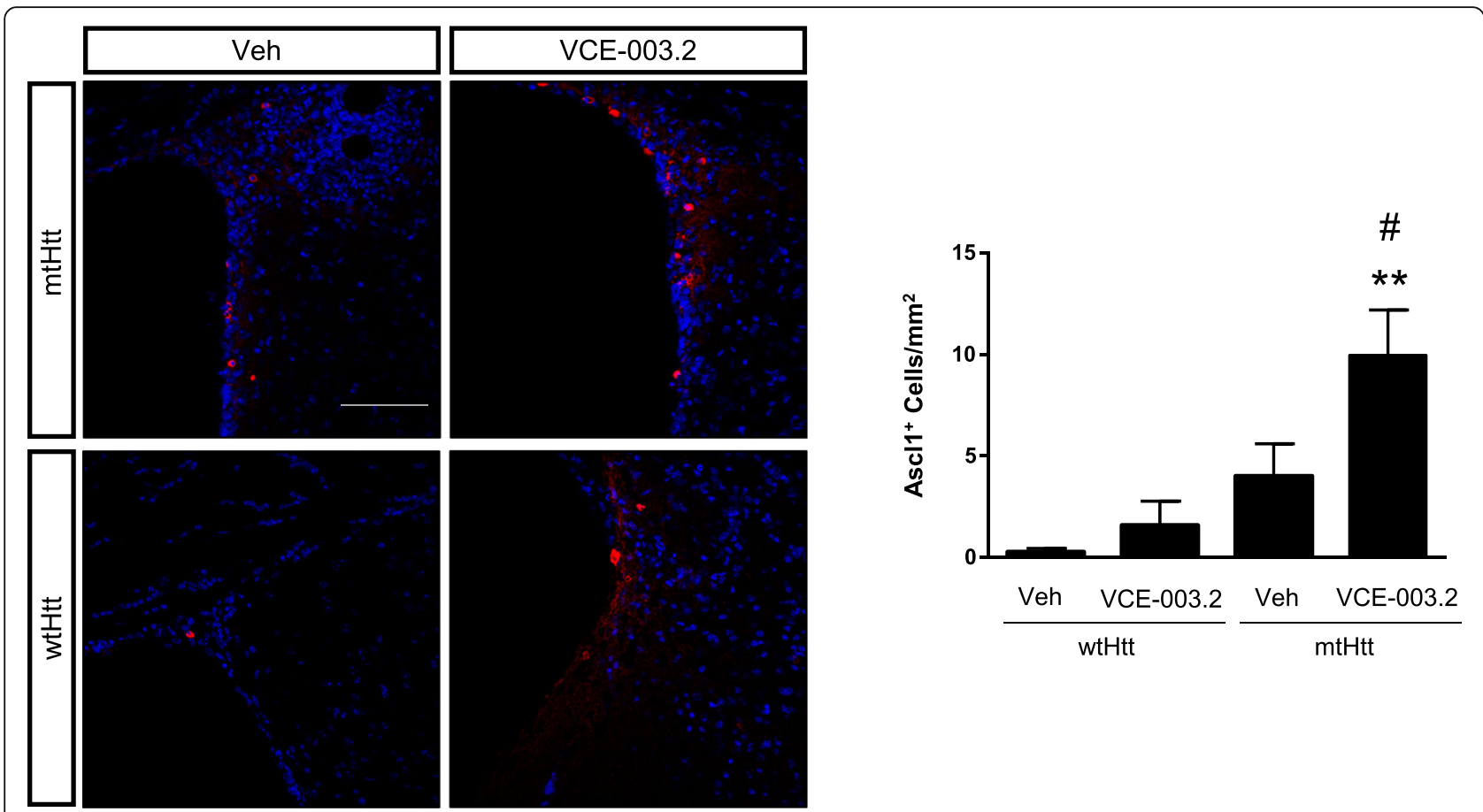

Fig. 6 Subventricular zone neural progenitor mobilization is increased by oral administration of VCE-003.2. Mice were analyzed 4 weeks after lesion induced by AAV-htt16Q and AAV-htt94Q bilateral injection and daily treatment with vehicle or VCE-003.2 (10 mg/kg). Confocal microscopy characterization of the SVZ was performed with Ascl1-specific antibody in the indicated experimental groups. Quantification of transit amplifying progenitors labelled with Ascl1. AAV-htt-16Q (Vehicle and VCE-003.2, $n=5$ each) and AAV-htt94Q (Vehicle and VCE-003.2, $n=5$ each). Statistics: One-way ANOVA. $F=10.12 ; R^{2}=0.65 . \# \#<0.01 ; q=4.25$ AAV-htt94Q VCE-003.2 vs. AAV-htt94Q Veh and ${ }^{* *} p<0.01 ; q=7.12$ AAV-htt94Q VCE003.2 vs. AAV-htt16Q Veh. Scale bar, $100 \mu \mathrm{m}$

undesired side-effects constitutes an attractive strategy to solve these limitations.

PPAR $\gamma$ receptors are required for appropriate neurogenesis as it controls neural progenitor cell proliferation and differentiation [25]. Noteworthy, the positive effect of PPAR $\gamma$ in neurogenesis, requires fine-tune regulation, as either its ablation or overactivation may hamper neuronal differentiation [26]. Under pathological conditions, for instance under an inflammatory insult, PPAR $\gamma$ activation can restore neurogenesis and cognitive impairment [27]. Similarly, PPAR $\gamma$ activation can restore neurogenesis in the OH-DA model of Parkinson's disease [28] and prevent amyloid-beta-induced cell death of human neural stem cells [29]. In HD models, the administration of PPARy agonists protects from striatal neurodegeneration, attenuates neuroinflammation and decreases oxidative damage [30-32], supporting PPAR $\gamma$ as a valid target for the management of HD.

CBD is the most widely investigated phytocannabinoid devoid of psychotomimetic actions, and whereas its precise molecular mechanism of action remains the subject of research, some CBD actions, including its protective effect in counteracting amyloid-induced inflammation and neurogenesis deficits, are mediated by PPAR $\gamma$ receptors [33]. Hence, CBD administration can restore hippocampal neurogenesis deficits induced by different nervous system insults such as amyloid-beta pathology, chronic unpredictable stress and aging [34]. Other plant-derived cannabinoids such as CBG and tetrahydrocannabinolic acid regulate PPARY activity $[15,35]$ and, hence, constitute interesting template structures for the development of new molecules with improved selectivity, reduced side-effects and better pharmacokinetic profile. Different strategies have been applied to improve CBD pharmacological properties. Fluorinated derivatives or quinone modifications have successfully generated new cannabinoid molecules with better translational perspectives (e.g., HUF-101, VCE-004). Thus, HUF-101 possesses improved anxiolytic, antidepressant and antipsychotic properties compared to the original CBD molecule [36]. Regarding CBG, its aminoquinone derivative VCE-003.2 has demonstrated efficacy as a neuroprotective molecule in HD [14], Parkinson's disease [21] and amyotrophic lateral sclerosis models [37]. Noteworthy, the VCE-003.2 compound is devoid of the side effects seen with full PPAR $\gamma$-agonists and, hence, does not interfere with osteoblast differentiation and is less adipogenic [14].

Cell replacement therapy has demonstrated efficacy in HD experimental models and in preliminary studies in patients [38]. Exogenous cell grafts of either fetal tissue 


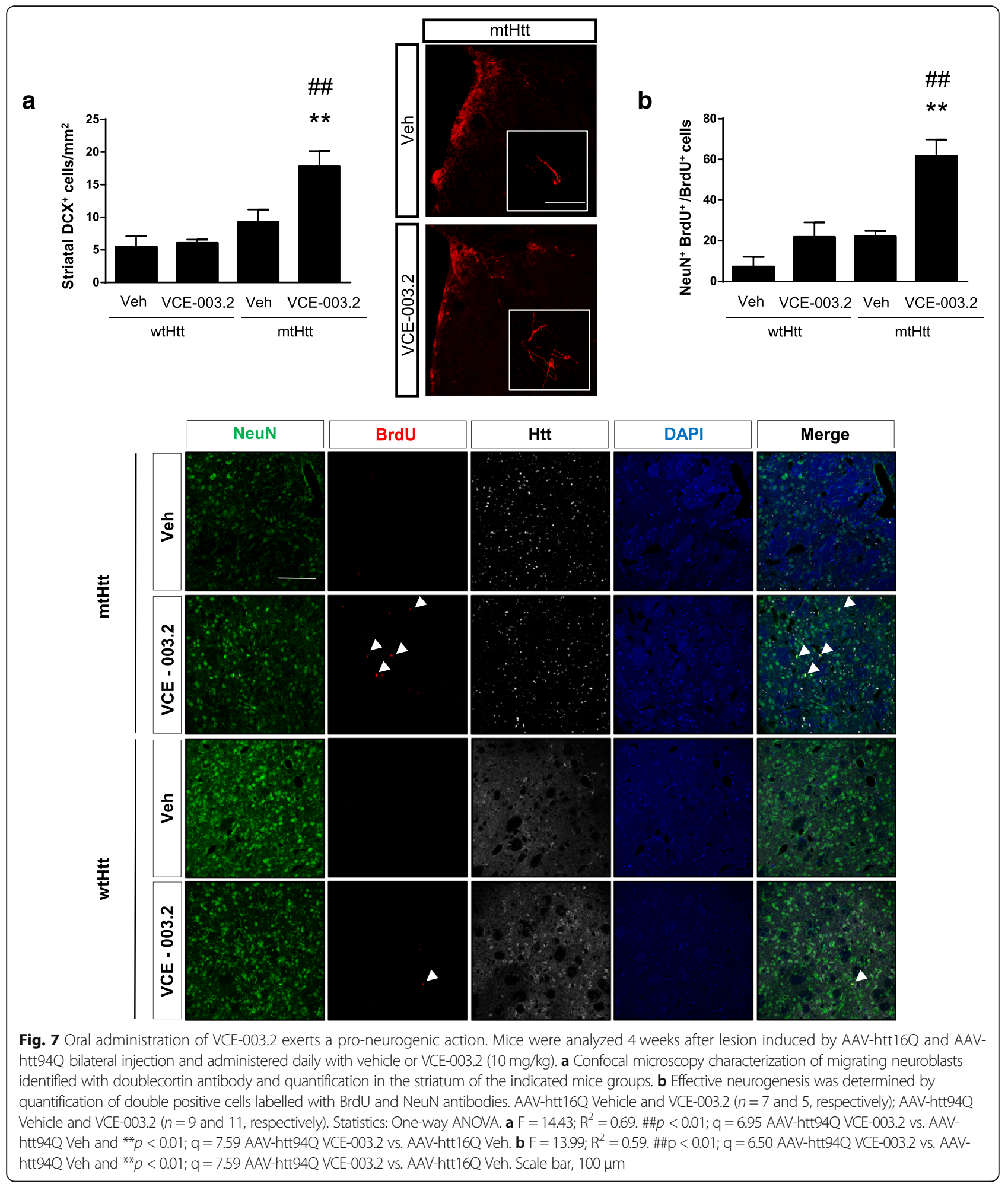

or stem-cell derived neurons are able to survive in the striatum, as well as integrate and ameliorate motor symptoms and survival, however they face various challenges that impede their development for disease-modifying strategy. Considering that in HD postmortem tissue an increased
SVZ cell proliferation and neurogenesis is evident [39], promoting endogenous SVZ-derived striatal neurogenesis constitutes an alternative approach of interest. Promoting SVZ neurogenesis by gene therapy-mediated delivery of BDNF and noggin successfully delayed progression of the 
disease in the R6/2 mouse model [40, 41], and the same approach induced neurogenesis in adult squirrel monkeys [40]. These findings evidence that, even if endogenous newly-born neurons express mutant huntingtin, neurogenesis is effective and able to counteract, at least in part, neurodegeneration-evoked symptoms. In this scenario, pharmacological promotion of adult neurogenesis by cannabinoids $[42,43]$ may constitute a plausible alternative to gene therapy. In addition, cannabinoids could be used to promote ES-derived striatal neurogenesis ex vivo for mechanistic studies or cell replacement therapies.

In summary, our findings demonstrate that oral administration of VCE-003.2 exerts a neuroprotective action in a striatal neurodegeneration model that is accompanied by an improved endogenous neurogenic response. The capability of VCE-003.2 to increase effective neurogenesis suggests that this CBG derivative may possess the ability to act as a disease-modifying drug rather than only a symptomatic reliever.

\section{Conclusions}

Oral administration of the cannabigerol derivative VCE-003.2 is neuroprotective and improves subventricular zone-derived neurogenesis in response to mutant huntingtin-induced neurodegeneration. These findings are relevant in the search for novel therapeutic strategies against Huntington's disease progression, considering the lack of undesired side actions of this novel cannabinoid-derived molecule and good bioavailability upon oral administration.

\section{Additional files}

Additional file 1: Microsomal Metabolic Stability. Pooled human liver microsomes (final protein concentration $0.5 \mathrm{mg} / \mathrm{mL}$ ), $0.1 \mathrm{M}$ phosphate buffer pH 7.4 and the test compounds (VCE-003.2, CBG, verapamil and dextromethorphan) were pre-incubated at $37^{\circ} \mathrm{C}$ prior to the addition of $1 \mathrm{mM} \mathrm{NADPH}$ to initiate the reaction. The final incubation volume was $25 \mu \mathrm{L}$. Each compound was incubated for 0, 5, 15, 30 and $45 \mathrm{~min}$. The control (minus NADPH) was incubated for 45 min only. The reactions were stopped by the addition of $50 \mu \mathrm{L}$ methanol containing internal standard at the appropriate time points. The incubation plates were centrifuged at $2500 \mathrm{rpm}$ for $20 \mathrm{~min}$ at $4^{\circ} \mathrm{C}$ to precipitate the protein. Following protein precipitation, the sample supernatants were analyzed using LC-MS/MS. From a plot of In peak area ratio (compound peak area/ internal standard peak area) against time, the gradient of the line was determined. Subsequently, half-life and intrinsic clearance was calculated using the equations below: Elimination rate constant $(k)=(-$ gradient). Half-life $\left(\mathrm{t}_{1 / 2}\right)(\mathrm{min})=\frac{0.693}{k}$. Intrinsic Clearance $\left(\mathrm{CL}_{\text {int }}\right)(\mu \mathrm{L} / \mathrm{min} / \mathrm{mg}$ protein $)$ $=\frac{V \times 0.693}{t_{1 / 2}}$. where $V=$ Incubation volume $\mathrm{mL} / \mathrm{mg}$ microsomal protein. (PDF $373 \mathrm{~kb}$ )

Additional file 2: Cytochrome P450 Inhibition (IC50 Determination). CYP1A Inhibition. VCE-003.2 (0.1, 0.25, 1, 2.5, 10, $25 \mu \mathrm{M}$ in DMSO; final DMSO concentration $=0.3 \%$ ) was incubated with human liver microsomes $(0.25 \mathrm{mg} / \mathrm{mL})$ and NADPH $(1 \mathrm{mM})$ in the presence of the probe substrate ethoxyresorufin $(0.5 \mu \mathrm{M})$ for $5 \mathrm{~min}$ at $37^{\circ} \mathrm{C}$. The selective CYP1A inhibitor, alpha-naphthoflavone, was screened alongside the test compounds as a positive control. CYP2B6 Inhibition. VCE-003.2 (0.1, 0.25, 1, 2.5, 10, $25 \mu \mathrm{M}$ in DMSO; final DMSO concentration $=0.3 \%$ ) was incubated with human liver microsomes $(0.1 \mathrm{mg} / \mathrm{mL})$ and NADPH $(1 \mathrm{mM})$ in the presence of the probe substrate bupropion $(110 \mu \mathrm{M})$ for $5 \mathrm{~min}$ at $37^{\circ} \mathrm{C}$. The selective CYP2B6 inhibitor, ticlopidine, was screened alongside the test compounds as a positive control. CYP2C8 Inhibition. VCE-003.2 (0.1, 0.25, 1, 2.5, 10, $25 \mu \mathrm{M}$ in DMSO; final DMSO concentration $=0.3 \%$ ) was incubated with human liver microsomes $(0.25 \mathrm{mg} / \mathrm{mL})$ and NADPH $(1 \mathrm{mM})$ in the presence of the probe substrate paclitaxel $(7.5 \mu \mathrm{M})$ for $30 \mathrm{~min}$ at $37^{\circ} \mathrm{C}$. The selective CYP2C8 inhibitor, montelukast, was screened alongside the test compounds as a positive control. CYP2C9 Inhibition. VCE-003.2 (0.1, 0.25, 1, 2.5, 10, $25 \mu \mathrm{M}$ in DMSO; final DMSO concentration $=0.3 \%$ ) was incubated with human liver microsomes $(1 \mathrm{mg} / \mathrm{mL})$ and NADPH $(1 \mathrm{mM})$ in the presence of the probe substrate tolbutamide $(120 \mu \mathrm{M})$ for $60 \mathrm{~min}$ at $37^{\circ} \mathrm{C}$. The selective CYP2C9 inhibitor, sulphaphenazole, was screened alongside the test compounds as a positive control. CYP2C19 Inhibition. VCE-003.2 (0.1, 0.25, 1, 2.5, 10, $25 \mu \mathrm{M}$ in DMSO; final DMSO concentration $=0.3 \%$ ) was incubated with human liver microsomes $(0.5 \mathrm{mg} / \mathrm{mL})$ and NADPH $(1 \mathrm{mM})$ in the presence of the probe substrate mephenytoin $(25 \mu \mathrm{M})$ for $60 \mathrm{~min}$ at $37^{\circ} \mathrm{C}$. The selective CYP2C19 inhibitor, tranylcypromine, was screened alongside the test compounds as a positive control. CYP2D6 Inhibition. VCE-003.2 (0.1, 0.25, 1, 2.5, 10, $25 \mu \mathrm{M}$ in DMSO; final DMSO concentration $=0.3 \%)$ was incubated with human liver microsomes $(0.5 \mathrm{mg} / \mathrm{mL})$ and NADPH $(1 \mathrm{mM})$ in the presence of the probe substrate dextromethorphan $(5 \mu \mathrm{M})$ for $5 \mathrm{~min}$ at $37^{\circ} \mathrm{C}$. The selective CYP2D6 inhibitor, quinidine, was screened alongside the test compounds as a positive control. CYP3A4 Inhibition. VCE-003.2 (0.1, 0.25, 1, 2.5, 10, $25 \mu \mathrm{M}$ in DMSO; final DMSO concentration $=0.3 \%$ ) was incubated with human liver microsomes $(0.1 \mathrm{mg} / \mathrm{mL})$ and $\mathrm{NADPH}(1 \mathrm{mM})$ in the presence of the probe substrate midazolam $(2.5 \mu \mathrm{M})$ for $5 \mathrm{~min}$ at $37^{\circ} \mathrm{C}$. The selective CYP3A4 inhibitor, ketoconazole, was screened alongside the test compounds as a positive control. CYP3A4 Inhibition. VCE-003.2 (0.1, 0.25, 1, 2.5, 10, $25 \mu \mathrm{M}$ in DMSO; final DMSO concentration $=0.3 \%$ ) was incubated with human liver microsomes $(0.5 \mathrm{mg} / \mathrm{mL})$ and NADPH $(1 \mathrm{mM})$ in the presence of the probe substrate testosterone $(50 \mu \mathrm{M})$ for $5 \mathrm{~min}$ at $37^{\circ} \mathrm{C}$. The selective CYP3A4 inhibitor, ketoconazole, was screened alongside the test compounds as a positive control. For the CYP1A incubations, the reactions were terminated by methanol, and the formation of the metabolite, resorufin, was monitored by fluorescence (excitation wavelength $=535 \mathrm{~nm}$, emission wavelength $=$ $595 \mathrm{~nm}$ ). For the CYP2B6, CYP2C9, CYP2C19, CYP2D6, and CYP3A4 incubations, the reactions were terminated by methanol. The samples were centrifuged, and the supernatants combined for the simultaneous analysis of 4-hydroxytolbutamide, 4-hydroxymephenytoin, dextrorphan, and 1hydroxymidazolam by LC-MS/MS. Hydroxybupropion, 6a-hydroxypaclitaxel and 6 ß-hydroxytestosterone were analyzed separately by LC-MS/MS. A decrease in the formation of the metabolites compared to vehicle control was used to calculate IC50 values. (PDF $323 \mathrm{~kb}$ )

Additional file 3: $\mathrm{hERG}$ Channel Inhibition ( $\mathrm{C}_{50}$ Determination). The experiments were performed on an lonWorks ${ }^{\mathrm{TM}} \mathrm{HT}$ instrument (Molecular Devices Corporation), which automatically performs electrophysiology measurements in 48 single cells simultaneously in a specialized 384-well plate (PatchPlate $\left.{ }^{\mathrm{TM}}\right)$. The cells used were Chinese hamster ovary $(\mathrm{CHO})$ cells stably transfected with hERG (cell-line obtained from Cytomyx, UK). A single-cell suspension was prepared in extracellular solution (Dulbecco's phosphate buffered saline with calcium and magnesium pH 7-7.2) and aliquots added to each well of a PatchPlate ${ }^{T M}$. Cells were positioned over a small hole at the bottom of each well by applying a vacuum beneath the plate to form an electrical seal. The resistance of each seal was measured via a common ground-electrode in the intracellular compartment and individual electrodes placed into each of the upper wells. Electrical access to the cell was achieved by circulating a perforating agent, amphotericin, underneath the PatchPlate ${ }^{\mathrm{TM}}$ and then measuring the pre-compound hERG current. An electrode is positioned in the extracellular compartment and a holding potential of $-80 \mathrm{mV}$ applied for $15 \mathrm{~s}$. The hERG channels were then activated by applying a depolarizing step to $+40 \mathrm{mV}$ for $5 \mathrm{~s}$ and then clamped at $-50 \mathrm{mV}$ for $4 \mathrm{~s}$ to elicit the hERG tail current, before returning to $-80 \mathrm{mV}$ for $0.3 \mathrm{~s}$. VCE003.2 were added to the upper wells of the PatchPlate ${ }^{\mathrm{Tm}}$. Solutions were prepared by diluting $10 \mathrm{mM}$ DMSO solutions of the test compound into extracellular buffer such that the final concentrations tested are 0.008 , $0.04,0.2,1,5$ and $25 \mu \mathrm{M}$ (final DMSO concentration 0.25\%). Quinidine, an established hERG inhibitor, was included as a positive control and buffer containing $0.25 \%$ DMSO was included as a negative control. Post- 
compound currents were then expressed as a percentage of precompound currents and plotted against concentration for each compound. Where concentration-dependent inhibition is observed, the data are fitted and $I C_{50}$ values were calculated. (PDF $322 \mathrm{~kb}$ )

Additional file 4: AMES Data Summary. AMES Experimental Procedure. Approximately ten million bacteria are exposed in triplicate to VCE-003-.2 $(7.8,15.6,31.3,62.5,125$ and $250 \mu \mathrm{g} / \mathrm{ml})$, a negative control (vehicle) and a positive control for $90 \mathrm{~min}$ in medium containing a low concentration of histidine (sufficient for about 2 doublings). The cultures were then diluted into indicator medium lacking histidine and dispensed into 48 wells of a 384 well plate (micro-plate format, MPF). The plate was incubated for $48 \mathrm{~h}$ at $37^{\circ} \mathrm{C}$, and the number of wells showing growth were counted and compared to the vehicle control. An increase in the number of colonies of at least two-fold over baseline (mean +SD of the vehicle control) and a dose response indicates a positive response. An unpaired, one-sided Student's T-test was used to identify conditions that are significantly different from the vehicle control. Where indicated, S9 fraction from the livers of Aroclor 1254-treated rats was included in the incubation at a final concentration of 4.5\%. An NADPH-regenerating system is also included to ensure a steady supply of reducing equivalents. The strains used in this study were S. typhimurium TA98 (hisD3052, rfa, uvrB/pKM10 for detection of frame-shift mutations) and S. typhimurium TA100 (hisG45, rfa, uvrB/pKM101 for detection of base-pair substitutions). VCE-003.2 was assessed for its mutagenic potential in the AMES reverse mutation assay. This test was performed in the absence and presence of $\mathrm{S} 9$ metabolic activation. VCE-003.2 was found to be negative for genotoxicity in this AMES study. The positive controls all behaved as expected. (PDF $568 \mathrm{~kb}$ )

Additional file 5: Effect of oral VCE-003.2 on plasmatic biomarkers. Plasma samples from the indicated groups of animals $(n=6)$ were pooled and subjected to mouse cytokine array (ARY028; R\&D Systems) and mouse adipokine array (ARY013; R\&D Systems) analysis. The relative expression of the indicated biomarkers is shown. (PDF $338 \mathrm{~kb}$ )

Additional file 6: 3-Nitroproprionic acid model of striatal neurodegeneration. 16-week- old C57BL/6 N male mice (Harlan Ibérica, Barcelona, Spain) were subjected to seven intraperitoneal (i.p.) injections of $50 \mathrm{mg} / \mathrm{kg} 3-\mathrm{NP}$ (one injection each every $12 \mathrm{~h}$ prepared in phosphatebuffered saline (PBS)]. 3-NP-treated animals and their respective nonlesioned controls (injected with PBS) were used for pharmacological studies with VCE-003.2. Treatments consisted of oral gavage every $24 \mathrm{~h}$ with VCE-003.2 at a dose of $10 \mathrm{mg} / \mathrm{kg}$ using sesame oil as vehicle. $12 \mathrm{~h}$ after the last injection of 3-NP motor activity, hindlimb clasping and kyphosis were evaluated as previously described [12]. Animals were euthanized at the indicated time after huntingtin-AAV infection or $12 \mathrm{~h}$ after the last injection of 3NP and their brains removed. Statistical analysis: One-way ANOVA followed by the Tuckey's post hoc test was used to determine the statistical significance. All the in vivo data were expressed as mean \pm SEM. Kruskal-Wallis test was used to determine the statistical in the case of non-parametric analysis. a) Hindlimb Clasping ( $F=8.069 ; p=0.0047)$ post hoc test: $p=0.00363 \mathrm{NP}$ vs Veh; Locomotor activity ( $F=18.62 ; p=0.0001)$ post hoc test $p<0.00013 \mathrm{NP}$ vs Veh, $p=$ $0.00273 \mathrm{NP}+\mathrm{VCE}-003.2$ vs 3NP; Kyphosis $(\mathrm{F}=28.24 p<0.0001)$ post hoc test: $p<0.00013 \mathrm{NP}$ vs Veh, $p<0.00013 \mathrm{NP}+\mathrm{VCE}-003.2$ vs $3 \mathrm{NP}$. b) TNF-a ( $F=18.17 p=0.0028)$ post hoc test: $p=0.00273 \mathrm{NP}$ vs Veh, $p=0.0138$ $3 N P+$ VCE-003.2 vs 3NP. IL-6 (Kruskal-Wallis statistic $=6.880 p=0.0071$ ) post hoc test: $p=0.0265$ 3NP vs Veh. c) Average number of neurons per field ( $F=15.69 p=0.0012$ ) post hoc test: $p=0.00113 \mathrm{NP}$ vs Veh, $p=0.0086$ $3 \mathrm{NP}+\mathrm{VCE}-003.2 \mathrm{vs} 3 \mathrm{NP}$; Number of $\mathrm{Iba} 1^{+}$cells $(\mathrm{F}=10.82 p=0.0040)$ post hoc test: $p=0.01013 \mathrm{NP}$ vs Veh, $p=0.00593 \mathrm{NP}+\mathrm{VCE}-003.2$ vs 3NP. (PDF $325 \mathrm{~kb}$ )

\section{Abbreviations}

AAV: Adeno associated virus; CBG: Cannabigerol; HD: Huntington's disease; Htt: Huntingtin; MSN: Medium spiny neuron; PPAR: Peroxisome proliferatoractivated receptor; SVZ: Subventricular zone

\section{Acknowledgements}

We are thankful to J. Díaz-Alonso and L. Bellochio for intellectual input to the project, assistance designing and preparing AAV constructs and particles; E.
Resel for grant administration and the rest of Galve-Roperh, Guzmán and Muñoz laboratories for enriching scientific environment.

\section{Funding}

This work was supported by the MINECO grant RTC-2015-3364 to EM and IGR cofounded by the European Development Regional Fund in the Framework of the Operative Program "Reinforcement of research, technological development and innovation". IGR was also supported by grant PI15-00310 and PI18-00941 cofinanced by the European Development Regional Fund "A way to achieve Europe" and EM by the MINECO grant SAF2017-87701-R. JA and JPL were supported by FPI and FPU program fellowship (Ministerio de Educación, Cultura y Deporte) and DGR by Fundación Tatiana de Guzmán el Bueno. BP is a predoctoral fellow supported by the i-PFIS program, Instituto de Salud Carlos III (IFI15/00022; European Social Fund "Investing in your future").

\section{Availability of data and materials}

The datasets used and/or analyzed during the current study are available from the corresponding author on reasonable request.

\section{Authors' contributions}

$J A, J P L, B P, R B, C N, A R, D G R$ and EGT performed in vivo and in vitro experiments; JA, JPL, BP, CN, IGR and EM collected and analyzed the data. IGR and EM managed and designed the overall study; MG, EM and IGR contributed to the literature research; JA and BP performed statistical analysis and MG, EM and IGR wrote the manuscript. All authors read and approved the final manuscript.

\section{Ethics approval and consent to participate}

Animal studies were approved by ethics committee of Complutense University and Cordoba University (Spain). Consent to participate is not applicable.

\section{Consent for publication}

Not applicable.

\section{Competing interests}

EM is scientific advisors of Emerald Health Pharmaceuticals.

\section{Author details}

'Instituto Ramón y Cajal de Investigación Sanitaria (IRYCIS), Ctra. Colmenar Viejo, km, 9100 Madrid, Spain. ²Departamento de Bioquímica y Biología Molecular and Instituto Universitario de Investigación Neuroquímica, Universidad Complutense, Madrid, Spain. ${ }^{3}$ Centro de Investigación Biomédica en Red sobre Enfermedades Neurodegenerativas (CIBERNED), Madrid, Spain. ${ }^{4}$ Instituto Maimónides de Investigación Biomédica de Córdoba (IMIBIC), Córdoba, Spain. ${ }^{5}$ Departamento de Biología Celular, Fisiología e Inmunología, Universidad de Córdoba, Córdoba, Spain. ${ }^{6}$ Hospital Universitario Reina Sofía, Córdoba, Spain. ${ }^{7}$ Emerald Health Pharmaceuticals, San Diego, USA.

\section{Received: 22 November 2018 Accepted: 15 February 2019}

\section{Published online: 08 March 2019}

\section{References}

1. Ross CA, Aylward EH, Wild EJ, Langbehn DR, Long JD, Warner JH, Scahill Rl, Leavitt BR, Stout JC, Paulsen JS, Reilmann R, Unschuld PG, Wexler A, Margolis RL, Tabrizi SJ. Huntington disease: Natural history, biomarkers and prospects for therapeutics. Nat Rev Neurol. 2014;10:204-16.

2. Conforti P, Besusso D, Bocchi VD, Faedo A, Cesana E, Rossetti G, Ranzani V, Svendsen CN, Thompson LM, Toselli M, Biella G, Pagani M, Cattaneo E. Faulty neuronal determination and cell polarization are reverted by modulating HD early phenotypes. Proc Natl Acad Sci U S A. 2018;115:E762-71.

3. Lim RG, Salazar LL, Wilton DK, King AR, Stocksdale JT, Sharifabad D, Lau AL, Stevens B, Reidling JC, Winokur ST, Casale MS, Thompson LM, Pardo M, AGG D-B, Straccia M, Sanders P, Alberch J, Canals JM, Kaye JA, Dunlap M, Jo L, May H, Mount E, Anderson-Bergman C, Haston K, Finkbeiner S, Kedaigle AJ, Gipson TA, Yildirim F, Ng CW, Milani P, Housman DE, Fraenkel E, Allen ND, Kemp PJ, Atwal RS, Biagioli M, Gusella JF, ME MD, Akimov SS, Arbez N, Stewart J, Ross CA, Mattis VB, Tom CM, Ornelas L, Sahabian A, Lenaeus L, Mandefro B, Sareen D, Svendsen CN. Developmental alterations in Huntington's disease neural cells and pharmacological rescue in cells and mice. Nat Neurosci. 2017;20:648-60. 
4. Godin JD, Colombo K, Molina-Calavita M, Keryer G, Zala D, Charrin BC, Dietrich P, Volvert M-L, Guillemot F, Dragatsis I, Bellaiche Y, Saudou F, Nguyen L, Humbert S. Huntingtin Is Required for Mitotic Spindle Orientation and Mammalian Neurogenesis. Neuron. 2010;67:392-406.

5. Barnat M, Le Friec J, Benstaali C, Humbert S. Huntingtin-Mediated Multipolar-Bipolar Transition of Newborn Cortical Neurons Is Critical for Their Postnatal Neuronal Morphology. Neuron. 2017;93:99-114.

6. Di Marzo V, Stella N, Zimmer A. Endocannabinoid signalling and the deteriorating brain. Nat Rev Neurosci. 2015;16:30-42.

7. Blázquez C, Chiarlone A, Sagredo O, Aguado T, Pazos MR, Resel E, Palazuelos J, Julien B, Salazar M, Börner C, Benito C, Carrasco C, Diez-Zaera M, Paoletti P, Díaz-Hernández M, Ruiz C, Sendtner M, Lucas JJ, de Yébenes JG, Marsicano G, Monory K, Lutz B, Romero J, Alberch J, Ginés S, Kraus J, Fernández-Ruiz J, Galve-Roperh I, Guzmán M. Loss of striatal type 1 cannabinoid receptors is a key pathogenic factor in Huntington's disease. Brain. 2011;134:119-36.

8. Dowie MJ, Bradshaw HB, Howard ML, Nicholson LFB, Faull RLM, Hannan AJ, Glass M. Altered CB1 receptor and endocannabinoid levels precede motor symptom onset in a transgenic mouse model of Huntington's disease. Neuroscience. 2009;163:456-65.

9. McCaw EA, Hu H, Gomez GT, Hebb ALO, Kelly MEM, Denovan-Wright EM. Structure, expression and regulation of the cannabinoid receptor gene (CB1) in Huntington's disease transgenic mice. Eur J Biochem. 2004;271: 4909-20.

10. Van Laere K, Casteels C, Dhollander I, Goffin K, Grachev I, Bormans G, Vandenberghe W. Widespread decrease of type 1 cannabinoid receptor availability in Huntington disease in vivo. J Nucl Med. 2010;51:1413-7.

11. Volkow ND, Baler RD, Compton WM, Weiss SRB. Adverse Health Effects of Marijuana Use. N Engl J Med. 2014;370:2219-27.

12. Valdeolivas S, Navarrete C, Cantarero I, Bellido ML, Muñoz E, Sagredo O. Neuroprotective Properties of Cannabigerol in Huntington's Disease: Studies in R6/2 Mice and 3-Nitropropionate-lesioned Mice. Neurotherapeutics. 2015; 12:185-99.

13. Chiang MC, Cheng YC, Nicol CJ, Lin KH, Yen CH, Chen SJ, Huang RN. Rosiglitazone activation of PPAR??-dependent signaling is neuroprotective in mutant huntingtin expressing cells. Exp Cell Res. 2015b;338:183-93.

14. Díaz-Alonso J, Paraíso-Luna J, Navarrete C, Del Río C, Cantarero I, Palomares B, Aguareles J, Fernández-Ruiz J, Bellido ML, Pollastro F, Appendino G, Calzado MA, Galve-Roperh I, Muñoz E. VCE-003.2, a novel cannabigerol derivative, enhances neuronal progenitor cell survival and alleviates symptomatology in murine models of Huntington's disease. Sci Rep. 2016;6:29789.

15. Granja AG, Carrillo-Salinas F, Pagani A, Gómez-Cañas M, Negri R, Navarrete C, Mecha M, Mestre L, Fiebich BL, Cantarero I, Calzado MA, Bellido ML, Fernandez-Ruiz J, Appendino G, Guaza C, Muñoz E. A cannabigerol quinone alleviates neuroinflammation in a chronic model of multiple sclerosis. J Neurolmmune Pharmacol. 2012;7:1002-16.

16. Díaz-Alonso J, Aguado T, Wu C-S, Palazuelos J, Hofmann C, Garcez P, Guillemot F, Lu H-C, Lutz B, Guzmán M, Galve-Roperh I. The CB (1) cannabinoid receptor drives corticospinal motor neuron differentiation through the Ctip2/ Satb2 transcriptional regulation axis. J Neurosci. 2012;32:16651-65.

17. Chiarlone A, Bellocchio L, Blazquez C, Resel E, Soria-Gomez E, Cannich A, Ferrero JJ, Sagredo O, Benito C, Romero J, Sanchez-Prieto J, Lutz B, Fernandez-Ruiz J, Galve-Roperh I, Guzman M. A restricted population of CB1 cannabinoid receptors with neuroprotective activity. Proc Natl Acad Sci. 2014;111:8257-62

18. Deiana S, Watanabe A, Yamasaki Y, Amada N, Arthur M, Fleming S, Woodcock H, Dorward P, Pigliacampo B, Close S, Platt B, Riedel G. Plasma and brain pharmacokinetic profile of cannabidiol (CBD), cannabidivarine (CBDV), $\Delta$ 9-tetrahydrocannabivarin (THCV) and cannabigerol (CBG) in rats and mice following oral and intraperitoneal administration and CBD action on obsessive-compulsive behav. Psychopharmacology (Berl). 2012;219:859-73.

19. Arlotta P, Molyneaux BJ, Chen J, Inoue J, Kominami R, Macklis JD. Neuronal Subtype-Specific Genes that Control Corticospinal Motor Neuron Development In Vivo. Neuron. 2005;45:207-21.

20. Ruiz-Calvo A, Maroto IB, Bajo-Grañeras R, Chiarlone A, Gaudioso Á, Ferrero JJ, Resel E, Sánchez-Prieto J, Rodríguez-Navarro JA, Marsicano G, GalveRoperh I, Bellocchio L, Guzmán M. Pathway-Specific Control of Striatal Neuron Vulnerability by Corticostriatal Cannabinoid CB1 Receptors. Cereb Cortex. 2018;28:307-22

21. García C, Gómez-Cañas M, Burgaz S, Palomares B, Gómez-Gálvez Y, PalomoGaro C, Campo S, Ferrer-Hernández J, Pavicic C, Navarrete C, Luz Bellido M García-Arencibia M, Ruth Pazos M, Muñoz E, Fernández-Ruiz J. Benefits of
VCE-003.2, a cannabigerol quinone derivative, against inflammation-driven neuronal deterioration in experimental Parkinson's disease: possible involvement of different binding sites at the PPARy receptor. J Neuroinflammation. 2018;15:19.

22. Shohayeb B, Diab M, Ahmed M, Ng DCH. Factors that influence adult neurogenesis as potential therapy. Transl Neurodegener. 2018;7:4.

23. Brooks SP, Dunnett SB. Mouse Models of Huntington's Disease. Curr Top Behav Neurosci. 2015;22:101-33.

24. Saft C, von Hein SM, Lücke T, Thiels C, Peball M, Djamshidian A, Heim B, Seppi K. Cannabinoids for Treatment of Dystonia in Huntington's Disease. J Huntingtons Dis. 2018;7:167-73.

25. Stergiopoulos A, Politis PK. The role of nuclear receptors in controlling the fine balance between proliferation and differentiation of neural stem cells. Arch Biochem Biophys. 2013;534:27-37.

26. Taheri M, Salamian A, Ghaedi K, Peymani M, Izadi T, Nejati AS, Atefi A, Nematollahi M, Ahmadi Ghahrizjani F, Esmaeili M, Kiani Esfahani A, Irani S, Baharvand $\mathrm{H}$, Nasr-Esfahani MH. A ground state of PPARy activity and expression is required for appropriate neural differentiation of hESCs. Pharmacol Rep. 2015;67:1103-14.

27. Ormerod BK, Hanft SJ, Asokan A, Haditsch U, Lee SW, Palmer TD. PPARY activation prevents impairments in spatial memory and neurogenesis following transient illness. Brain Behav Immun. 2013;29:28-38.

28. Bonato JM, Bassani TB, Milani H, Vital MABF, de Oliveira RMW. Pioglitazone reduces mortality, prevents depressive-like behavior, and impacts hippocampal neurogenesis in the 6-OHDA model of Parkinson's disease in rats. Exp Neurol. 2018;300:188-200.

29. Chiang M-C, Nicol CJ, Cheng Y-C, Lin K-H, Yen C-H, Lin C-H. Rosiglitazone activation of PPARy-dependent pathways is neuroprotective in human neural stem cells against amyloid-beta-induced mitochondrial dysfunction and oxidative stress. Neurobiol Aging. 2016;40:181-90.

30. Chiang M-C, Cheng Y-C, Nicol CJ, Lin K-H, Yen C-H, Chen S-J, Huang R-N. Rosiglitazone activation of PPARY-dependent signaling is neuroprotective in mutant huntingtin expressing cells. Exp Cell Res. 2015a;338:183-93.

31. Chiang M-C, Chern Y, Huang R-N. PPARgamma rescue of the mitochondrial dysfunction in Huntington's disease. Neurobiol Dis. 2012;45:322-8.

32. Jin J, Albertz J, Guo Z, Peng Q, Rudow G, Troncoso JC, Ross CA, Duan W. Neuroprotective effects of PPAR- $\gamma$ agonist rosiglitazone in N171-82Q mouse model of Huntington's disease. J Neurochem. 2013;125:410-9.

33. Esposito G, Scuderi C, Valenza M, Togna Gl, Latina V, de Filippis D, Cipriano M, Carratù MR, luvone T, Steardo L. Cannabidiol reduces A -induced neuroinflammation and promotes hippocampal neurogenesis through PPARY involvement. PLoS One. 2011;6:e28668.

34. Campos AC, Fogaça MV, Scarante FF, Joca SRL, Sales AJ, Gomes FV, Sonego $A B$, Rodrigues NS, Galve-Roperh I, Guimarães FS. Plastic and neuroprotective mechanisms involved in the therapeutic effects of cannabidiol in psychiatric disorders. Front Pharmacol. 2017;8:269.

35. Nadal X, del Río C, Casano S, Palomares B, Ferreiro-Vera C, Navarrete C, Sánchez-Carnerero C, Cantarero I, Bellido ML, Meyer S, Morello G, Appendino G, Muñoz E. Tetrahydrocannabinolic acid is a potent PPARY agonist with neuroprotective activity. Br J Pharmacol. 2017;174:4263-76.

36. Breuer A, Haj CG, Fogaça MV, Gomes FV, Silva NR, Pedrazzi JF, Del Bel EA, Hallak JC, Crippa JA, Zuardi AW, Mechoulam R, Guimarães FS. Fluorinated Cannabidiol Derivatives: Enhancement of Activity in Mice Models Predictive of Anxiolytic. Antidepressant and Antipsychotic Effects. PLoS One. 2016;11: e0158779.

37. Rodríquez-Cueto C, Santos-García I, García-Toscano L, Espejo-Porras F, Bellido M, Fernández-Ruiz J, Muñoz E, de Lago E. Neuroprotective effects of the cannabigerol quinone derivative VCE-003.2 in SOD1G93Atransgenic mice, an experimental model of amyotrophic lateral sclerosis. Biochem Pharmacol. 2018;157:217-26.

38. Rosser A, Svendsen CN. Stem cells for cell replacement therapy: A therapeutic strategy for HD? Mov Disord. 2014;29:1446-54.

39. Curtis MA, Penney EB, Pearson AG, van Roon-Mom WMC, Butterworth NJ, Dragunow M, Connor B, Faull RLM. Increased cell proliferation and neurogenesis in the adult human Huntington's disease brain. Proc Natl Acad Sci U S A. 2003;100:9023-7.

40. Benraiss A, Toner MJ, Xu Q, Bruel-Jungerman E, Rogers EH, Wang F, Economides AN, Davidson BL, Kageyama R, Nedergaard M, Goldman SA. Sustained mobilization of endogenous neural progenitors delays disease progression in a transgenic model of huntington's disease. Cell Stem Cell. 2013;12:787-99.

41. Cho SR, Benraiss A, Chmielnicki E, Samdani A, Economides A, Goldman SA. Induction of neostriatal neurogenesis slows disease progression in a 
transgenic murine model of Huntington disease. J Clin Invest. 2007;117: 2889-902.

42. Galve-Roperh I, Chiurchiù V, Díaz-Alonso J, Bari M, Guzmán M, Maccarrone M. Cannabinoid receptor signaling in progenitor/stem cell proliferation and differentiation. Prog Lipid Res. 2013;52:633-50.

43. Prenderville JA, Kelly ÁM, Downer EJ. The role of cannabinoids in adult neurogenesis. Br J Pharmacol. 2015;172:3950-63.

Ready to submit your research? Choose BMC and benefit from:

- fast, convenient online submission

- thorough peer review by experienced researchers in your field

- rapid publication on acceptance

- support for research data, including large and complex data types

- gold Open Access which fosters wider collaboration and increased citations

- maximum visibility for your research: over $100 \mathrm{M}$ website views per year

At $B M C$, research is always in progress.

Learn more biomedcentral.com/submissions 